\title{
Análise e visualização do domínio Internacionalização da Educação Superior no Brasil
}

\author{
Nancy Sánchez-Tarragó \\ Doutora; Universidade Federal de Rio Grande do Norte, Natal, RN, Brasil \\ nancita1973@gmail.com \\ Raimundo Nonato Macedo dos Santos \\ Doutor; Universidade Federal de Pernambuco, Recife, PE, Brasil \\ rnmacedo@uol.com.br \\ Leilah Santiago Bufrem \\ Doutora; Universidade Federal de Pernambuco, Recife, PE, Brasil \\ santiagobufrem@gmail.com
}

\begin{abstract}
Resumo: Caracteriza e visualiza as redes de pesquisadores brasileiros e suas interrelações a partir da produção de artigos científicos e da participação em grupos de pesquisa formalizados no domínio Internacionalização da Educação Superior. Apresenta referencial teórico sobre a internacionalização da educação superior e a abordagem metodológica de análise de domínio. Utiliza a análise de domínio, combinando técnicas bibliométricas, de análise de redes sociais e a análise do conteúdo dos textos do corpus, constituído de 146 artigos de periódicos científicos e trabalhos em eventos a partir de busca nas bases de dados Scopus, Web of Science (coleção principal e SciELO Citation Index), SciELO e Redalyc. Utiliza as métricas e visualizações das redes com Gephi 9.0.2. Constata que, apesar de incipiente, existe uma comunidade de pesquisadores no Brasil organizando-se em torno do domínio Internacionalização da Educação Superior, formalizada inclusive em grupos de pesquisa certificados. Conclui que, embora com pouca parceria internacional e disseminada em fontes predominantemente nacionais, a produção científica discute temas relevantes, reflexos das principais preocupações relacionadas com a geopolítica do conhecimento, a mercantilização da educação e as estratégias de internacionalização.
\end{abstract}

Palavras-chave: Internacionalização da educação superior. Análise de domínio. Análise de redes sociais. Mapas de ciência. Brasil

\section{Introdução}

A internacionalização da educação superior constitui um tema cada vez mais presente, tanto na agenda da gestão universitária como na literatura científica. Definese como o processo de incorporar a dimensão internacional/intercultural na missão, 
propósitos e funções das instituições universitárias (KNIGHT, 2004) e tem sido visto como catalizador de melhorias na qualidade do ensino e da pesquisa, e dos processos de integração e cooperação regional e mundial. Visa, também, em outros casos, ao posicionamento no mercado de bens e serviços educativos para a geração de ingressos financeiros, promovendo assim a competição entre instituições e países. Estudos anteriores têm constatado o crescimento das publicações científicas sobre o tema em todo o mundo, fundamentalmente, a partir dos primeiros anos da primeira década dos anos 2000 (DAL-SOTO; ALVES; SOUZA, 2017; KEHM; TEICHLER, 2007; SANCHEZ-TARRAGÓ; SANTOS; BUFREM, 2014, 2015). Esses estudos constatam o predomínio de autores e publicações provenientes dos Estados Unidos, Reino Unido, Canadá e Austrália, que são também os principais destinos de estudantes internacionais e os mercados fundamentais de serviços educativos e, cujas produções científicas são veiculadas através de publicações e bases de dados de alta visibilidade.

Contudo, na América Latina também se produzem cada vez mais estudos sobre internacionalização da educação superior e aparecem e se consolidam grupos e redes de pesquisa. No entanto, como assinala Didou-Aupetit (2014), os grupos de especialistas ainda são escassos, muitas vezes estruturados em torno de líderes. Os autores latino-americanos, embora com alto índice de produtividade, são pouco reconhecidos e citados por seus pares, em parte porque seus trabalhos são veiculados em revistas e canais de menor visibilidade, entre outras circunstâncias que refletem a geopolítica do conhecimento, analisada em outras contribuições (SÁNCHEZTARRAGÓ; BUFREM; SANTOS, 2015).

O Brasil, junto com a Argentina e o México, tem sido pioneiro tanto no apoio aos programas e processos de internacionalização nas universidades, como em indagações ao respeito, atendendo um leque de temas que vão desde as políticas de cooperação, a mobilidade, a internacionalização do curriculum, entre outros temas relacionados (DIDOU-AUPETIT, 2014). Ainda, no que diz respeito ao Brasil, alguns poucos trabalhos têm buscado caracterizar a produção científica na temática, destacando-se o capítulo de livro Internationalization of Higher Education: A Balance of the Literature in Brazil, de Sampaio e Saes (2014), que analisou uma amostra de 32 trabalhos (entre artigos de periódicos, capítulos de livros e monografias) e o artigo de periódico de Morisini e Nascimento (2017) titulado 
Internacionalização da educação superior no Brasil: a produção recente em teses e dissertações, que analisou 23 monografias.

Uma análise preliminar da produção brasileira sobre Internacionalização da Educação Superior, com foco em redes de pesquisadores e tendo como fundamentos teóricos as abordagens da análise de domínio e da análise de redes sociais, foi realizada por Sánchez-Tarragó, Santos e Bufrem (2018). Neste estudo, considera-se a Internacionalização da Educação Superior como um domínio científico, constituído pela inter-relação, por exemplo, entre os autores, grupos e redes de pesquisa, instituições, periódicos, eventos e categorias conceituais, imbricados em coordenadas espaciotemporais determinadas.

Com o intuito de analisar a configuração do domínio Internacionalização da Educação Superior, outras explorações têm sido feitas no marco do pós-doutorado em Ciência da Informação de uma das autoras deste artigo, utilizando métodos bibliométricos e de análise de redes sociais combinados com aproximações históricas e epistemológicas (SANCHEZ-TARRAGÓ; SANTOS; BUFREM, 2014, 2015; SANCHEZ-TARRAGÓ; BUFREM; SANTOS, 2016). Esses estudos têm permitido caracterizar a estrutura intelectual da produção analisada, identificando-se os principais produtores de conhecimento, as publicações mais relevantes no domínio, os termos mais utilizados e suas relações, alguns dos marcos paradigmáticos que configuram as abordagens dos autores do domínio e as vinculações interdisciplinares, seja pelas distintas formações dos autores, seja pelas influências intelectuais interdisciplinares sobre as quais se baseiam os trabalhos.

Nesse sentido, a presente contribuição constitui um aprofundamento teórico e empírico do trabalho de Sánchez-Tarragó, Santos e Bufrem (2018) e uma continuação da análise do domínio Internacionalização da Educação Superior, desta vez, com foco no marco espacial da produção científica brasileira e as redes de pesquisadores. Segue-se assim a recomendação de Smiraglia (2015) quando assevera que cada domínio deve ser analisado exaustivamente e continuamente, incluindo suas interseções com outros domínios, dado que o domínio está sempre em constantes mudanças, embora isso não seja aparente para aqueles nele envolvidos.

O trabalho tem como objetivo caracterizar as redes de pesquisadores brasileiros e suas inter-relações com a temática Internacionalização da Educação Superior a partir da produção de artigos científicos e sua participação em grupos de 
pesquisa, como uma das alternativas de construir e visualizar o domínio em questão. Está estruturado conforme segue: a seção 2 apresenta um breve referencial teórico sobre internacionalização da educação superior e a abordagem metodológica de análise de domínio; na seção 3 estão apresentados os procedimentos metodológicos enquanto, na seção 4 discorre-se sobre os principais resultados e sua discussão. $\mathrm{Na}$ última seção, são sintetizadas algumas conclusões derivadas do estudo.

\section{0 contexto atual da internacionalização da educação superior}

Durante as discussões conceituais acerca do termo internacionalização no contexto da educação superior, geralmente se faz referência às raízes antigas desta prática, quando os "estudantes" da antiga Grécia e da época medieval cruzavam espaços geográficos em busca de novos conhecimentos. Contudo, como destaca Monzón (2014), a internacionalização de hoje designa uma ideia muito diferente do que significava ao final do século IX, durante o século XIX, e incluso, até finais do século XX.

Para los romanos, como para los chinos o para cualquier ciudadano de un imperio de aquellas épocas, "Mundo" era lo cercano. Lo conquistado y lo conquistable. Hacia finales del S.XX, surge una idea del Mundo, supuestamente más homogénea, menos relativa, menos perceptual. Es un Mundo inmerso en una realidad cada vez más compleja, fruto del constante proceso de globalización que abarca aspectos como el de la economía, la política y la cultura (MONZÓN, 2014, p. 66).

No contexto atual, a internacionalização das universidades adquire um novo sentido, associando-se e influenciando-se por outros fenômenos como a globalização e a mercantilização da educação superior. De modo geral, a internacionalização faz referência a uma mudança cultural que visa impregnar de uma dimensão internacional/intercultural todos os processos que envolvem o ensino, a pesquisa e a extensão. Vários trabalhos dão conta do deslocamento conceitual e a mudança no eixo de dominação conceitual a favor do termo internacionalização, que se utiliza muitas vezes como guarda-chuva de outros processos como educação internacional, educação transnacional e a própria cooperação internacional (BENEITONE, 2014; KNIGHT, 2004; SÁNCHEZ-TARRAGÓ, SANTOS, BUFREM, 2014).

A transformação do termo internacionalização da educação superior não é só de índole semântica, mas traz junto modificações essenciais. As próprias motivações 
da internacionalização têm evoluído e se alguns anos atrás se privilegiavam os objetivos acadêmicos, hoje são as motivações de índole econômica, que configuram as estratégias e políticas nos contextos institucional e nacional (ALTBACH; KNIGHT, 2007; HERMO; PITELLI, 2008). Na Europa, o Processo de Bolonha, em 1999, que serviu de marco para a criação do Espaço Europeu de Educação Superior, foi também o indicador da transformação no âmbito dos acordos de cooperação entre universidades ao se ajustar aos termos do Acordo Geral de Comércio de Serviços (GATS, sigla sem inglês) da Organização Mundial do Comércio, cujo objetivo explícito é a liberalização do comércio de serviços, incluindo os educativos, em dimensão mundial (MONZÓN, 2014). Países como Austrália, Estados Unidos, Japão e Nova Zelândia também estão inseridos na onda de liberalização do comércio de serviços educativos usando o marco regulatório do GATS.

A discussão ideológica que acompanha a evolução da internacionalização da educação superior também permite distinguir entre uma perspectiva "neutra", acrítica, que assume a internacionalização como um processo inerentemente benéfico e outras perspectivas mais críticas que apontam a insustentabilidade de sua orientação mercantil (KNIGHT, 2013; MONCADA CERÓN, 2011; STEIN, 2017). Na América Latina, como destaca Didou-Aupetit (2014), em escala regional têm relevância as perspectivas de análise baseadas numa defesa ideológica da cooperação solidária e na crítica aos enfoques neocoloniais, assim como, reflexões que salientam a educação como bem público. Também é característico um marcado enfoque nacional, pois a internacionalização da educação superior e da ciência está atrelada aos contextos particulares dos países e das instituições de educação superior.

\subsection{A internacionalização da educação superior no Brasil}

Do acordo com Laus e Morosini (2005), a internacionalização da educação superior no Brasil tem seus primeiros indícios em paralelo com as reformas universitárias de 1968, quando se adota o modelo de universidade com base em pesquisa (modelo Humboldt) e segundo o estilo das universidades dos Estados Unidos e, como decorrência, estudantes brasileiros, em busca de pós-graduação, passaram a ser enviados para o exterior. Dessa forma, constituiu-se segundo um processo fragmentado, em nichos isolados das instituições universitárias, embora se observasse 
um interesse governamental para trabalhar nas linhas de interesses estratégicos do país, por meio de acordos de cooperação internacional.

Já partir da década de 1990, seguindo as tendências internacionais, a internacionalização da educação superior brasileira começa a ser considerada um fator chave, junto com exigências de políticas mais flexíveis na educação superior, melhorias na qualidade do processo educacional e a redução do papel do Estado. Assim, a Coordenação de Aperfeiçoamento de Pessoal do Nível Superior (CAPES) explicita a necessidade do estabelecimento de padrões internacionais para a avaliação das atividades de pós-graduação e pesquisa desenvolvidas pelas instituições públicas.

Precisamente nessa época "o fenómeno da mercantilização da educação superior acentua-se no bojo do processo de globalização e de disseminação das tecnologias de informação" (CARVALHO, 2013, p. 766). Face à crescente mercantilização da educação superior e a entrada em vigor dos GATS, no Brasil se acirra o debate sobre os riscos da inclusão da educação dentro dos serviços regulados pela Organização de Comércio Internacional, levando a um posicionamento contrário, tanto do governo brasileiro como das instituições públicas a favor de preservar a educação como um bem público.

Acompanhando o percurso cronológico de Laus e Morosini (2005) é possível notar que nos últimos decênios se produz um conjunto maior de processos e atividades de internacionalização nas instituições universitárias brasileiras, tais como programas de ensino de língua estrangeira, cursos em outros idiomas, pesquisas conjuntas, programas de mobilidade de estudantes, professores e pesquisadores, programas de duplo diploma, programas de educação a distância utilizando tecnologias da informação, entre outras. Embora, no contexto constitucional a internacionalização não esteja mencionada e até há pouco tempo estivesse ausente de legislações e políticas governamentais e institucionais, esse processo no Brasil se guia tanto pelos princípios que regem as relações internacionais brasileiras, quanto pelos princípios concernentes à educação e à ciência e tecnologia, isto é, à busca da cooperação entre os povos para o progresso da humanidade e a efetivação da integração latino-americana, inclusive em termos sociais e culturais (MARRARA, 2007).

O governo federal tem sido o ator fundamental nos processos de internacionalização com investimentos para o desenvolvimento científico das 
universidades públicas e a ampliação dos programas de pós-graduação. Junto com ele, agências governamentais como CAPES, Conselho Nacional de Desenvolvimento Científico e Tecnológico (CNPq) e Agência Brasileira de Cooperação (ABC), do Ministério de Relações Exteriores. A internacionalização da educação superior se concentra fundamentalmente na área da pesquisa e se desenvolve prioritariamente na pós-graduação (LAUS; MOROSINI, 2005). No entanto, o programa governamental Ciência sem Fronteiras, que funcionou desde 2011 até 2015, com o objetivo de que alunos de graduação e pós-graduação fizessem estágio no exterior com a finalidade de manter contato com sistemas educacionais competitivos em relação à tecnologia e inovação, atingiu a meta anunciada de conceder 101.446 bolsas de estudo no exterior, sendo $78 \%$ desse total na modalidade de graduação (CAPES, 2015). Avaliações posteriores do Ministério da Educação concluíram com o encerramento da modalidade de bolsas para graduação, focando novamente em editais para pósgraduação (BRASIL, 2017).

\subsection{Análise e visualização de domínios como enfoque metodológico}

A análise de domínio, proposta por Hjørland e Albrechtsen (1995), constitui um enfoque filosófico-realista e funcionalista que trata de encontrar as bases para as disciplinas informacionais em fatores externos às percepções subjetivas individuais. Hjørland (2017) baseia-se em Shapere (1977) para definir um domínio como o conjunto total de informação em que, idealmente, se pode encontrar a resposta a um problema determinado, sobretudo se o problema requer uma teoria. Portanto, pode ser uma área de experiência, um corpus de literatura, inclusive um sistema de indivíduos e práticas que partilham uma linguagem ou terminologia comum.

De acordo com esta perspectiva, a forma em que trabalham os membros de um domínio tem reflexos na organização do conhecimento, na sua estrutura, seus padrões de cooperação, formas de comunicação, linguagem e sistemas de informação. Portanto, um domínio tem uma natureza dual pois, por um lado, é uma organização intelectual e, por outro, uma organização social, em inter-relação simbiótica (HJØRLAND, 2017). Albrechtsen (2015) destaca que um domínio não é algo que está "lá fora", pronto para ser descoberto e descrito pelo analista, mas que é um campo de trabalho que vá construindo-se durante o próprio processo de análise. 
Analisar um domínio, portanto, implica interpretar as relações internas entre os componentes, por exemplo, entre os documentos, seus autores, suas intuições, suas teorias ou perspectivas epistemológicas, os conceitos e termos que utilizam.

Os métodos bibliométricos constituem parte do conjunto de enfoques metodológicos para realizar essa análise (HJØRLAND, 2002). Deve ser ressaltado que a análise de domínio não é neutra; sempre está guiada por uma perspectiva determinada. Portanto, diferentes teorias podem construir domínios diferentes, como também, por exemplo, a escolha de uma fonte para um mapeamento bibliométrico dará lugar a um domínio enquanto a escolha de outras, poderia fazer emergir outra configuração. Outro enfoque utilizado, muitas vezes em combinação com o bibliométrico, é a análise de redes sociais, um enfoque estrutural de sociologia da ciência, que estuda as interações sociais entre indivíduos, como essas ocorrem e qual a influência que uns indivíduos têm sobre outros. Baseia-se na ideia de que o padrão de laços sociais que se estabelece entre os indivíduos de um grupo ou uma comunidade tem importantes consequências para eles (FREEMAN, 2004). Sendo assim, a análise de redes sociais também se mostra útil para entender como determinada comunidade de discurso constrói e transfere o conhecimento, e como esses laços sociais configuram e delimitam domínios de conhecimento.

A utilização dos métodos e enfoques mencionados permitem a visualização de domínios através da criação de mapas de ciência: representações espaciais de como as disciplinas, campos, especialidades, documentos individuais e autores estão relacionados uns com outros (VARGAS-QUASADA; MOYA-ANEGÓN, 2007). Entre as técnicas mais utilizadas para construir esses mapas de ciência está a análise da coocorrência entre palavras-chave, autores, instituições e documentos, permitindo explorar as relações, tanto intelectuais como sociais que se estabelecem entre os autores, suas especialidades, instituições e seus enfoques teóricos-epistemológicos, por meio dos discursos materializados nos documentos (OLIVEIRA; GRÁCIO, 2013).

\section{Procedimentos metodológicos}

Esta pesquisa utiliza o enfoque metodológico da análise de domínio, combinando técnicas bibliométricas, de análise de redes sociais e a análise do conteúdo dos textos 
incluídos no estudo. Para a conformação do corpus, realizou-se uma busca nas bases de dados Scopus, Web of Science (WoS) (coleção principal e SciELO Citation Index), SciELO e Redalyc, em setembro de 2017. A estratégia de busca fundamentou-se nos termos "internationalization" AND "higher education" no campo integrado Title-Abstract-Keywords e "Brazil" no campo Address para as bases Scopus e WoS. O uso do termo "internationalisation" (variante s e z) em combinação com "higher education" para a busca (e não outros como "academic mobility") devese a sua consagração como termo guarda-chuva para designar os processos de internacionalização da educação superior (MOROSINI; NASCIMENTO, 2017). Os resultados filtrados se limitaram a artigos de periódicos científicos e trabalhos em eventos em que pelo menos um autor fosse afiliado a uma instituição brasileira

Para a SciELO e o Redalyc foram utilizadas variantes em português dos mesmos termos e critérios em campos similares, embora no caso do Redalyc, pelas limitações dos filtros de busca, foi necessária uma exaustiva revisão manual para garantir que os resultados se ajustassem aos parâmetros desejados. Adicionalmente, realizaram-se buscas na base de dados Education Resource Information Center (ERIC), mas somente seis registros foram obtidos, já incluídos nas buscas anteriores, pelo que não foram levados em consideração. Os registros procedentes do Redalyc passaram a ser inseridos manualmente em uma folha de Excel com os mesmos campos e etiquetas utilizados nas bases de WoS, Scopus e SciELO e gravados em formato CSV. Buscando uniformidade, verificou-se que todos os registros obtidos do Redalyc e da SciELO tiveram as palavras-chave em inglês (foram traduzidas nos casos necessários).

Os registros obtidos das cinco bases foram exportados para o software Vantage Point, com o qual se realizou a combinação das bases em uma só e a eliminação dos registros duplicados. A base final está conformada por 146 registros. A partir desses dados, procedeu-se à contagem de frequência e à produção de matrizes de coocorrência (palavras-chave, autor, palavras chave-instituições e coautoria). Empregou-se o enfoque da análise de redes sociais para caracterizar a estrutura da rede de coautoria e a relação entre a temática (representada por palavraschave), os autores e as instituições. As métricas e visualizações das redes realizaramse com Gephi 9.0.2. Utilizaram-se duas medidas de importância relativa dos nós na rede: 1) centralidade de autovetor, na qual um nó tem alta centralidade (importância, 
influência) se estiver conectado com nós centrais, e 2) centralidade de intermediação, que representa o potencial do nó de desempenhar-se como "intermediador" na rede, a partir da quantidade de vezes que serve de ponte para outros.

Foram recuperados os textos completos e se fez uma leitura flutuante dos títulos, resumos, seções principais e conclusões dos artigos para analisar as abordagens dos autores com relação às principais categorias temáticas identificadas por meio do estudo métrico e das visualizações realizadas.

O estudo se complementou com a identificação e caraterização espacial dos grupos de pesquisa brasileiros que abordam temáticas relacionadas com a internacionalização da educação superior. Para isso se realizou uma busca, em janeiro de 2018, no Diretório de Grupos de Pesquisa do CNPq, no título e palavras-chave das linhas de pesquisa, a partir dos seguintes pares de termos: internacionalização e educação, internacionalização e universidade, internacionalização e ensino, internacionalização e currículo, e mobilidade acadêmica. Foram recuperados 30 grupos e 34 linhas de pesquisa relacionados com a temática. Analisaram-se as variáveis: líder do grupo, integrantes, área predominante do grupo, instituição e estado. A triangulação metodológica permitiu o aprofundamento da compreensão do domínio Internacionalização da Educação Superior no Brasil.

\section{Resultados e discussão}

\subsection{Caracterização das fontes, autores e instituições}

Os 146 registros sobre internacionalização da educação superior se distribuem no marco temporal de 18 anos, entre o ano 2000 e 2017. Na Figura 1 (na qual foram excluídos registros de 2017 - cobertura incompleta do período), pode-se observar a partir de 2012 o maior crescimento da produção, com 11 artigos no ano e um pico máximo de 38 em 2016. O incremento entre 2011 e 2012, fundamentalmente em artigos de periódicos, também foi identificado no estudo de Sampaio e Saes (2014). Resulta interessante que, segundo essas autoras, é só partir de 2006 que a temática virou objeto de pesquisa dos cursos de graduação (monografias) e pós-graduação (teses e dissertações), o que sugere o início da institucionalização da produção de conhecimento na temática. 
Os trabalhos considerados na pesquisa foram publicados em 100 fontes (98 periódicos e dois anais de congresso). Dessas fontes, $56 \%$ só publicaram um artigo, o que sugere uma grande pulverização da temática. A maioria das fontes é nacional. Os periódicos brasileiros Avaliação: Revista da Avaliação da Educação Superior (publicada pela Rede de Avaliação Institucional da Educação Superior da Universidade Estadual de Campinas e da Universidade de Sorocaba) e a Revista Gestão Universitária na América Latina - GUAL (publicada pelo Instituto de Pesquisas e Estudos em Administração Universitária, da Universidade Federal de Santa Catarina) veicularam a maior quantidade de artigos sobre o tema, com 14 e 9, respectivamente. Ambas as revistas são de acesso aberto e estão atualmente em estratos diferentes de Qualis Periódico (2013-2016) segundo áreas. Por exemplo, para a área de Educação, a Avaliação: Revista da Avaliação da Educação Superior é A1 e Revista Gestão Universitária na América Latina é C; para Administração Pública e de Empresas, Ciências Contáveis e Turismo, ambos os periódicos são B2.

Figura 1- Distribuição de artigos de periódicos sobre internacionalização da educação superior. Brasil. 2000-2016

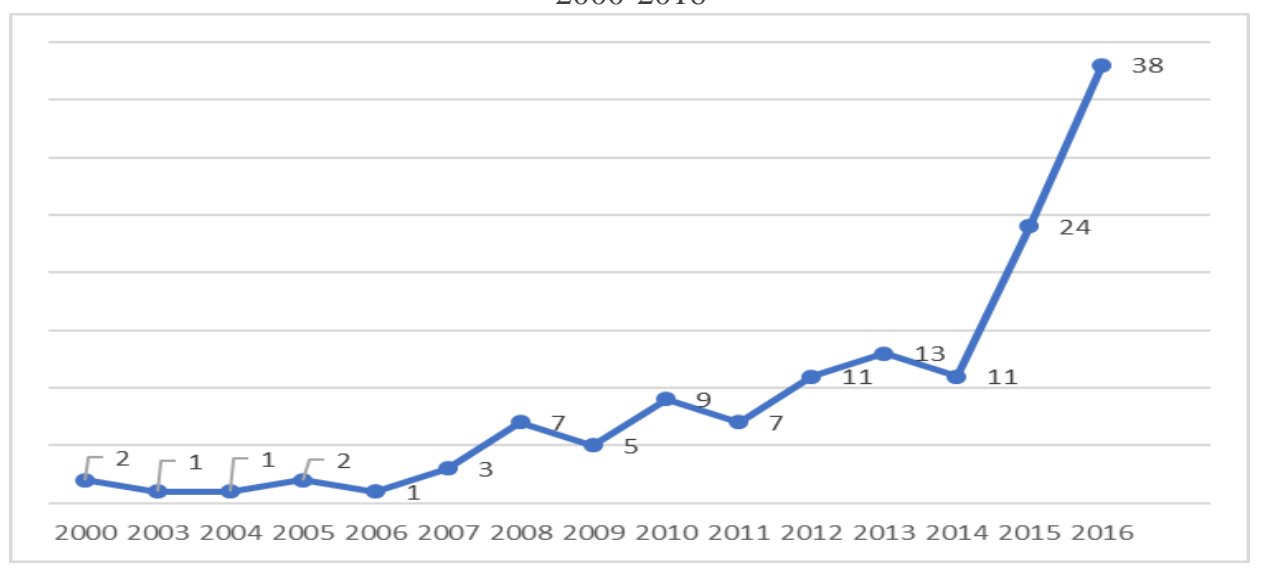

Fonte: Dados da pesquisa (2017).

Identificaram-se 270 autores distribuídos em 112 instituições e dez países (95\% do Brasil e o restante de Portugal, Espanha, Canadá, Argentina, Cuba, Estados Unidos, Irlanda, México e Suíça). Desse total, 32 autores têm dois ou mais artigos (a Tabela 1 mostra um recorte dessa lista). Os pesquisadores mais produtivos na temática têm uma longa trajetória acadêmica, vários possuem as categorias de professores titulares e associados, sendo alguns bolsistas de produtividade do CNPq. Isso se reflete na liderança de alguns deles em grupos de pesquisa sobre a temática, na ocupação de cargos e responsabilidades de assessoria em questões relacionadas com 
as relações internacionais na educação superior e na possibilidade de articulação de trabalhos em coautoria com estudantes de pós-graduação e com outros pesquisadores. Dos autores, 90\% trabalharam em parceria com um ou mais coautores, sendo majoritariamente das áreas de Ciências Humanas e Ciências Sociais Aplicadas, com destaque para Educação e Administração. Essa composição também foi encontrada nas 34 linhas de pesquisa do Diretório de Grupos de pesquisa do CNPq que abordam a temática. Os trabalhos de Sampaio e Saes (2014) e Morosini e Nascimento (2017) constataram resultados semelhantes. Com relação à relevância dos autores da área de Administração, Sampaio e Saes sugerem que no Brasil a introdução e disseminação da temática de Internacionalização da Educação Superior devem muito a essa área, com interesse nos processos de internacionalização e mercantilização ligados ao funcionamento do Mercado Comum do Sul (Mercosul).

Tabela 1 - Autores brasileiros com destaque na temática de Internacionalização da Educação Superior (2000-2017). N. trabalhos $\geq 2$

\begin{tabular}{|c|c|c|c|}
\hline Autor & Formação e categoria docente & $\begin{array}{c}\text { Instituição, } \\
\text { estado }\end{array}$ & $\begin{array}{l}\text { No. } \\
\text { trabalhos }\end{array}$ \\
\hline $\begin{array}{l}\text { Lima, Manolita } \\
\text { Correia }\end{array}$ & $\begin{array}{l}\text { Graduação em Ciências Sociais, } \\
\text { Doutorado em Educação }\end{array}$ & $\mathrm{ESPM}(\mathrm{SP})$ & 8 \\
\hline $\begin{array}{l}\text { Morosini, Marília } \\
\text { Costa }\end{array}$ & $\begin{array}{l}\text { Graduação em Ciências Sociais, } \\
\text { Doutorado em Educação. Professora } \\
\text { Titular }\end{array}$ & PUCRS (RS) & 8 \\
\hline Freitas, Maria Ester & $\begin{array}{l}\text { Graduação e Doutorado em } \\
\text { Administração de empresas. P. Titular }\end{array}$ & EAESP/FGV (SP) & 4 \\
\hline Archanjo, Renata & $\begin{array}{l}\text { Graduação em Psicologia e Doutorado } \\
\text { em Estudos da Linguagem. Professora } \\
\text { Associada }\end{array}$ & UFRN (RN) & 3 \\
\hline $\begin{array}{l}\text { Azevedo, Mário Luiz } \\
\text { Neves de }\end{array}$ & $\begin{array}{l}\text { Doutorado em Educação. Professor } \\
\text { Titular }\end{array}$ & UEM (PR) & 3 \\
\hline Riegel, Viviane & $\begin{array}{l}\text { Graduação em Administração, Mestrado } \\
\text { em Comunicação e Práticas de consumo }\end{array}$ & ESPM (SP) & 3 \\
\hline $\begin{array}{l}\text { Franco, Maria Estela } \\
\text { Dal Pai }\end{array}$ & $\begin{array}{l}\text { Graduação em Pedagogia e Doutorado } \\
\text { em Educação. Professora Titular }\end{array}$ & UFRGS (RS) & 2 \\
\hline Krawczyk, Nora Rut & Graduação e Doutorado em Educação & UNICAMP (SP) & 2 \\
\hline Leite, Denise & $\begin{array}{l}\text { Doutorado em Educação. Professora } \\
\text { Titular }\end{array}$ & UFRGS (RS) & 2 \\
\hline $\begin{array}{l}\text { Lo Bianco, Anna } \\
\text { Carolina }\end{array}$ & $\begin{array}{l}\text { Graduação em Psicologia e Doutorado } \\
\text { em Sociologia da Saúde Mental. } \\
\text { Professora Titular }\end{array}$ & UFRJ (RJ) & 2 \\
\hline Miura, Irene Kazumi & $\begin{array}{l}\text { Graduação em Psicologia e Doutorado } \\
\text { em Administração. Professora Associada }\end{array}$ & USP (SP) & 2 \\
\hline Stallivieri, Luciane & $\begin{array}{l}\text { Graduação em Letras e Doutorado em } \\
\text { Línguas Modernas }\end{array}$ & UCS (RS) & 2 \\
\hline
\end{tabular}

Fonte: Currículo Lattes dos autores estudados e dados da pesquisa (2018).

A análise da rede de coautoria dos autores (Figura 2) mostra uma rede de 242 nós (autores) com 76 clusters conectados por relações de coautoria. A rede se 
apresenta bastante desconexa, com ligações fracas em quase todos os clusters. Predominam os agrupamentos conformados por três ou menos autores. A visualização, feita a partir da métrica de centralidade de intermediação, permite identificar os autores que atuam como intermediários ou "porteiros" na rede, pois têm um alto grau de ligações diretas ou indiretas com outros autores. Nesse caso destacam-se Marilia Morosini, da Pontifícia Universidade Católica do Rio Grande do Sul (PUCRS) e Manolita Correia Lima, da Escola Superior de Propaganda e Marketing (ESPM), as autoras mais produtivas do corpus. Os resultados sugerem que Morosini é atualmente a autora com maior centralidade na temática, não só pelo quantitativo da produção, mas também porque essa se desenvolve por meio de muitas ligações que ocorrem com autores que também atuam como "porteiros" de outras redes (como o caso de Denise Leite, da Universidade Federal do Rio Grande do Sul [UFRGS]).

Figura 2 - Rede de coautoria. Internacionalização da Educação Superior no Brasil

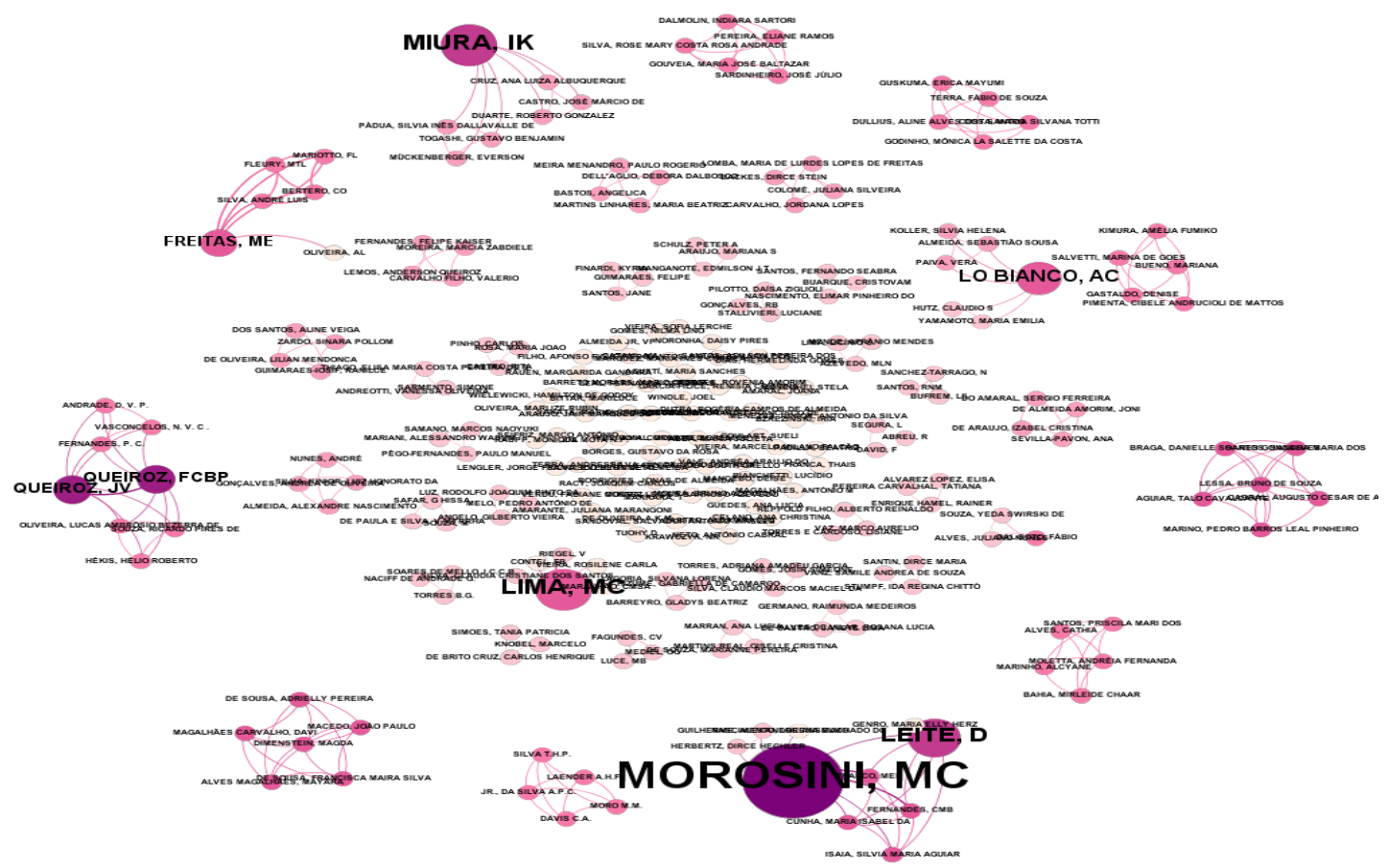

Fonte: Elaborado pelos autores (2018).

A busca no Diretório de Grupos de Pesquisa do CNPq permitiu constatar que esse cluster ao redor de Morosini está formalizado por meio do grande grupo de pesquisa UNIVERSITAS/RIES, com mais de 30 membros e liderado por essa pesquisadora. A esse grupo pertence a maioria dos coautores, com parcerias 
interinstitucionais e internacionais. O estudo de Sampaio e Saes (2014) também aponta Morosini como a autora com mais citações entre os autores nacionais no período estudado (1999-2012), seguida por Sonia Laus, coautora de Morosini em vários trabalhos muito citados nacionalmente.

Com relação às instituições de procedência dos autores, o estudo mostra o envolvimento de 112 instituições diferentes. Delas, 29 foram responsáveis por dois ou mais trabalhos. A Tabela 2 registra as dez primeiras posições enquanto produtividade, ocupadas por instituições brasileiras. Destacam-se as instituições sediadas em São Paulo e Rio Grande do Sul, predominando as instituições de educação superior (IES) públicas. É interessante o quantitativo da produção dos pesquisadores da Universidade Federal de Rio Grande do Norte (UFRN), única instituição entre aquelas das regiões Norte e Nordeste, com uma produção relevante na temática. A relação entre as instituições e os temas tratados dentro da Internacionalização será discutida mais a frente.

Tabela 2 - As dez instituições brasileiras mais produtivas na temática de Internacionalização da Educação Superior (2000-2017)

\begin{tabular}{llcc} 
Instituição & \multicolumn{1}{c}{ Estado } & Região & $\begin{array}{c}\text { Quantidade } \\
\text { de artigos }\end{array}$ \\
\hline USP & São Paulo & Sudeste & 17 \\
UFRGS & Rio Grande do Sul & Sul & 15 \\
UFRN & Rio Grande do Norte & $\begin{array}{c}\text { Nordeste } \\
\text { Centro- }\end{array}$ & 9 \\
UnB & Distrito Federal & Oeste & 9 \\
ESPM & São Paulo & Sudeste & 8 \\
PUCRS & Rio Grande do Sul & Sul & 7 \\
UFMG & Minas Gerais & Sudeste & 7 \\
UNICAMP & São Paulo & Sudeste & 7 \\
UFF & Rio de Janeiro & Sudeste & 6 \\
UFSC & Santa Catarina & Sul & 6 \\
\hline
\end{tabular}

\subsection{Relações dos pesquisadores e instituições com a temática Internacionalização da Educação Superior}

No trabalho de Sampaio e Saes (2014), que tem servido de comparação para o presente artigo, as autoras identificaram quatro grandes temas em torno dos quais se desenvolve a produção científica brasileira na temática: a) processos de comercialização da educação superior; b) estratégias de internacionalização no Brasil; 
c) mobilidade acadêmica e d) geopolítica: Mercosul e Processo de Bolonha. Cada um desses temas está articulado entre si e com outros subtemas, que por sua vez se conectam em discussões mais amplas e relacionadas. A Figura 3 é uma adaptação a partir do trabalho dessas autoras. Em negrito se destacam outras subtemáticas que têm sido identificadas por meio do presente estudo e que também se inserem nos grandes temas antes mencionados: reformas universitárias e educação transnacional, associadas aos processos de mercantilização da educação; programa Ciência sem Fronteiras, políticas de linguagem e ranking acadêmicos, em discussões relativas às estratégias de internacionalização e à mobilidade acadêmica, essa última também associada a trabalhos sobre multiculturalismo, regionalização, integração, internacionalização solidária; políticas de linguagem e avaliação e acreditação inseridas em temas mais amplos de questões geopolíticas vinculadas ao Mercosul e ao Processo de Bolonha.

Figura 3 - Principais temas e objetos de pesquisa em Internacionalização da Educação Superior

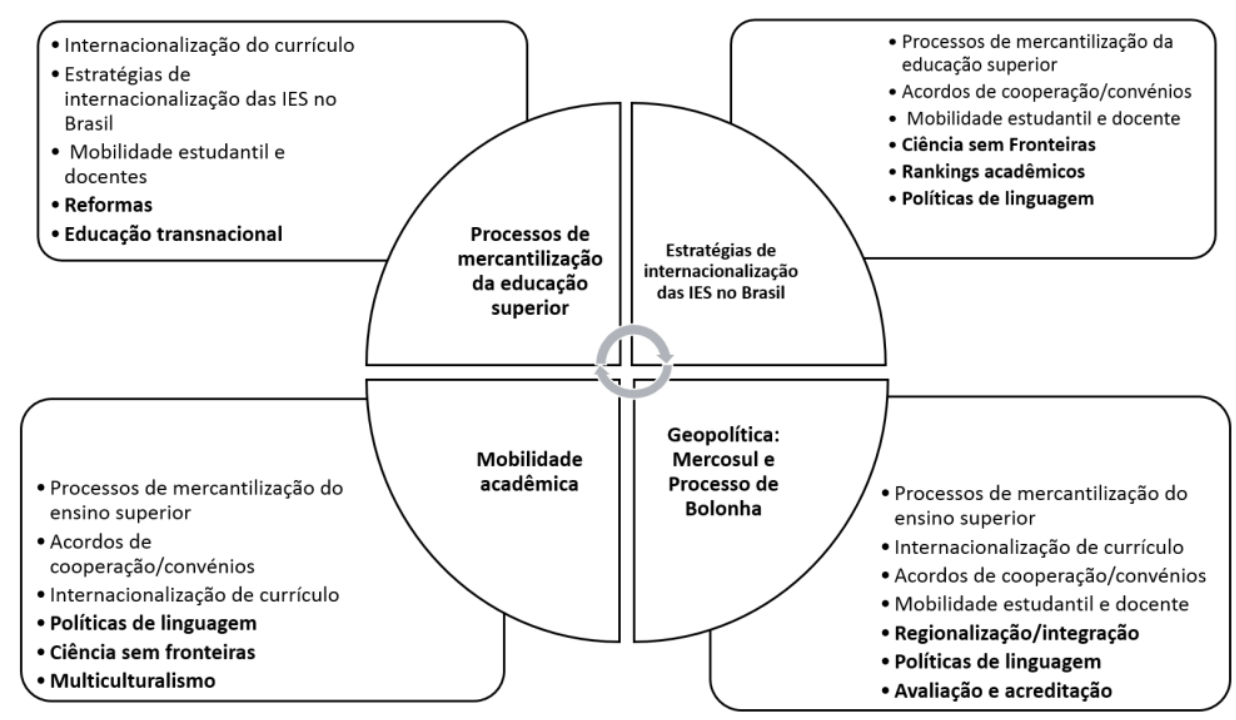

Fonte: Adaptado de Sampaio e Saes (2014).

Para analisar o envolvimento dos pesquisadores com as temáticas relacionadas com a Internacionalização da Educação Superior foram criadas matrizes de coocorrência entre as palavras-chave dos artigos e os autores, em ambos os casos, com mais de duas frequências no corpus (Figura 4). A visualização é feita por meio do algoritmo de detecção de comunidades do Gephi que mostra coloridos os nós com maior interação ou ligações. Assim é possível observar cinco comunidades ou 
conglomerados. O diâmetro do nó é proporcional à frequência e, a espessura da aresta é equivalente à intensidade da coocorrência.

Os conglomerados refletem os grandes temas mencionados anteriormente e permitem identificar autores "chave". Por exemplo, em cor verde destaca o nó Academic mobility, terceiro em tamanho depois dos nós que representam os termos mais genéricos, sinalizando o fato de que uma parte importante da pesquisa brasileira está focada na mobilidade acadêmica, com vertentes relacionadas com os estudantes internacionais e suas motivações para estudar no exterior, as políticas de linguagem (incluídas as problemáticas relacionadas com os programas Ciência sem Fronteiras e Idiomas sem Fronteiras), a educação intercultural e as estratégias de internacionalização.

Figura 4- Mapa de coocorrência de palavras-chave e autores no domínio Internacionalização da Educação Superior no Brasil

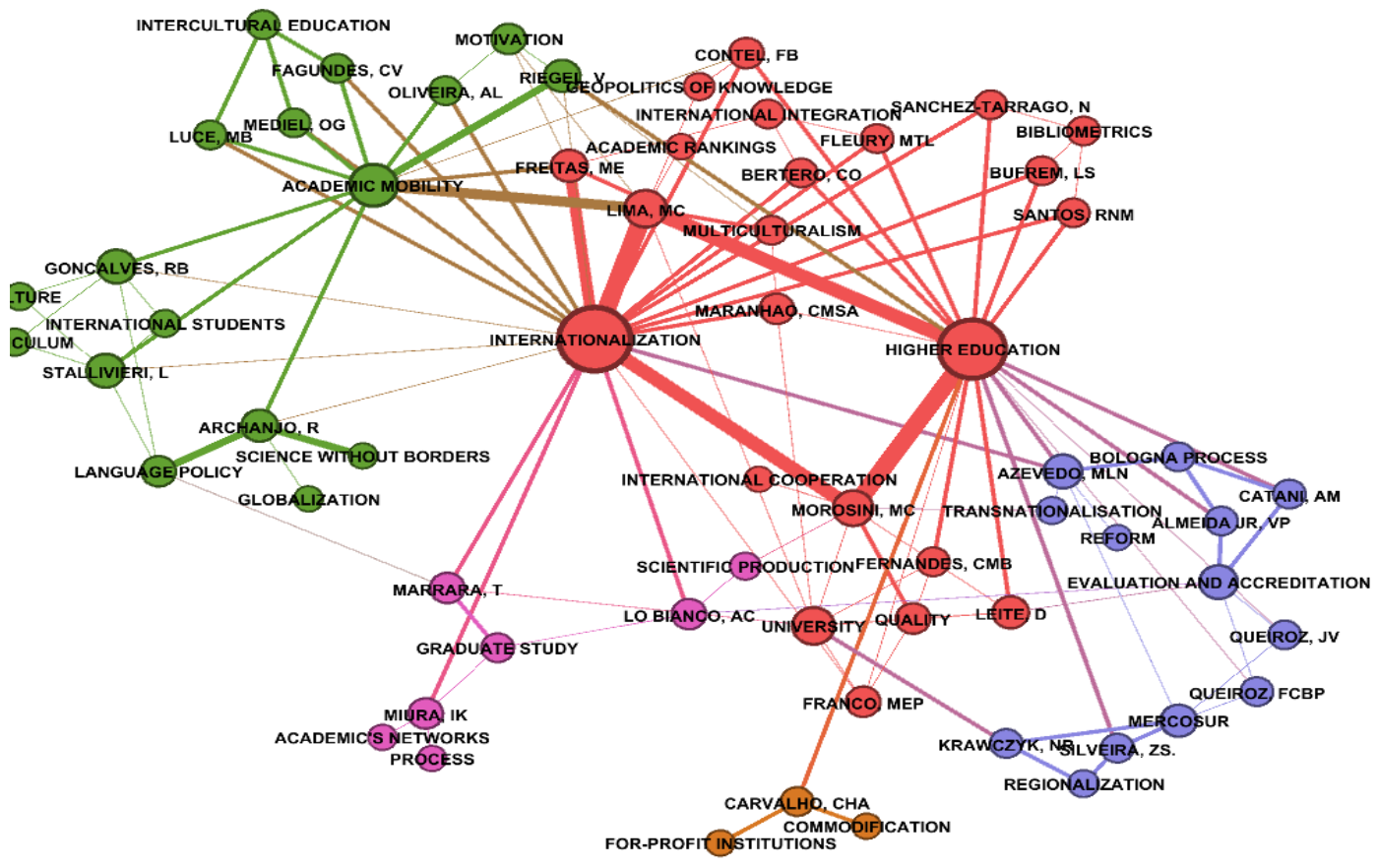

Fonte: Elaborado pelos autores (2018).

Essas temáticas são constituídas por objetos de pesquisas formalizados no marco de, pelo menos, quatro grupos de pesquisa do CNPq. A pesquisadora Manolita Correia Lima, líder de um dos grupos de pesquisa na temática Mobilidade acadêmica, se posiciona na rede como enlace entre esse termo e outros mais gerais do domínio Internacionalização da Educação Superior. Neste mesmo cluster destacam-se 
trabalhos que discutem as políticas de linguagem no Brasil no contexto da implantação do programa Ciência sem Fronteiras. Nesse tema, a pesquisadora Renata Archanjo (UFRN) tem a maior quantidade de contribuições. Os trabalhos problematizam a política linguística no Brasil e sua importância para a internacionalização e o incremento da produção científica e tecnológica.

O cluster na cor azul reflete as relações entre autores e temas de geopolítica vinculados ao Processo de Bolonha, Mercosul e a transnacionalização da educação, assim como aos processos de avaliação e acreditação. Destacam-se os autores Mario Luiz Neves de Azevedo, da Universidade Estadual de Maringá (UEM), e Afrânio Méndes Catani, da Universidade de São Paulo (USP), ambos pesquisadores de longa trajetória acadêmica na área de Educação. No cluster rosa vale a pena destacar autores e trabalhos que relatam experiências de internacionalização com perspectivas solidárias a partir da criação de universidades federais como espaços de integração latino-americana (ABBA; CORSETTI, 2016; MARTINS, 2010; MENENGHEL; AMARAL, 2016).

A Figura 5 representa a coocorrência entre palavras-chave e instituições, segundo a métrica de centralidade de autovetor. Neste caso, a centralidade e importância dos nós (instituição e palavra-chave) estão influenciadas pela relação com outros nós de alta centralidade. O diâmetro do nó é proporcional à frequência e, a espessura da aresta é equivalente à intensidade da coocorrência. A visualização sugere que as instituições mais centrais (em rosa mais escuro) estão situadas nos estados do Sul e Sudeste. É possível observar a centralidade da USP, seguida da UFRGS, ambas com alta produção sobre a temática.

A USP abrange diferentes temas de pesquisa, tanto aqueles que refletem a dimensão institucional da internacionalização, por exemplo, as políticas institucionais de internacionalização ou as mudanças nas grades curriculares (internacionalização do curriculum), como aqueles relacionados com a dimensão nacional, por exemplo, os programas governamentais de mobilidade ou as preocupações relativas a avaliação e acreditação de programas. No entanto, chama a atenção que embora o estado de São Paulo tenha a maior quantidade de grupos de pesquisa do $\mathrm{CNPq}$ na temática (7), nenhum deles faz parte da USP.

No caso da UFRGS, vários trabalhos remetem à dimensão regional/global da internacionalização, com discussões relacionadas à problemática da mercantilização 
da educação, da defesa da identidade nacional das instituições de educação superior e do emprego de indicadores de internacionalização apropriados para os contextos nacionais/locais. Embora essa universidade tampouco tenha grupos de pesquisa sobre a temática, constatou-se que alguns de seus autores trabalham com o grupo de pesquisa de Morosini da PUCRS.

Figura 5 - Mapa de coocorrência de palavras chaves e instituições. Internacionalização da Educação Superior. Brasil

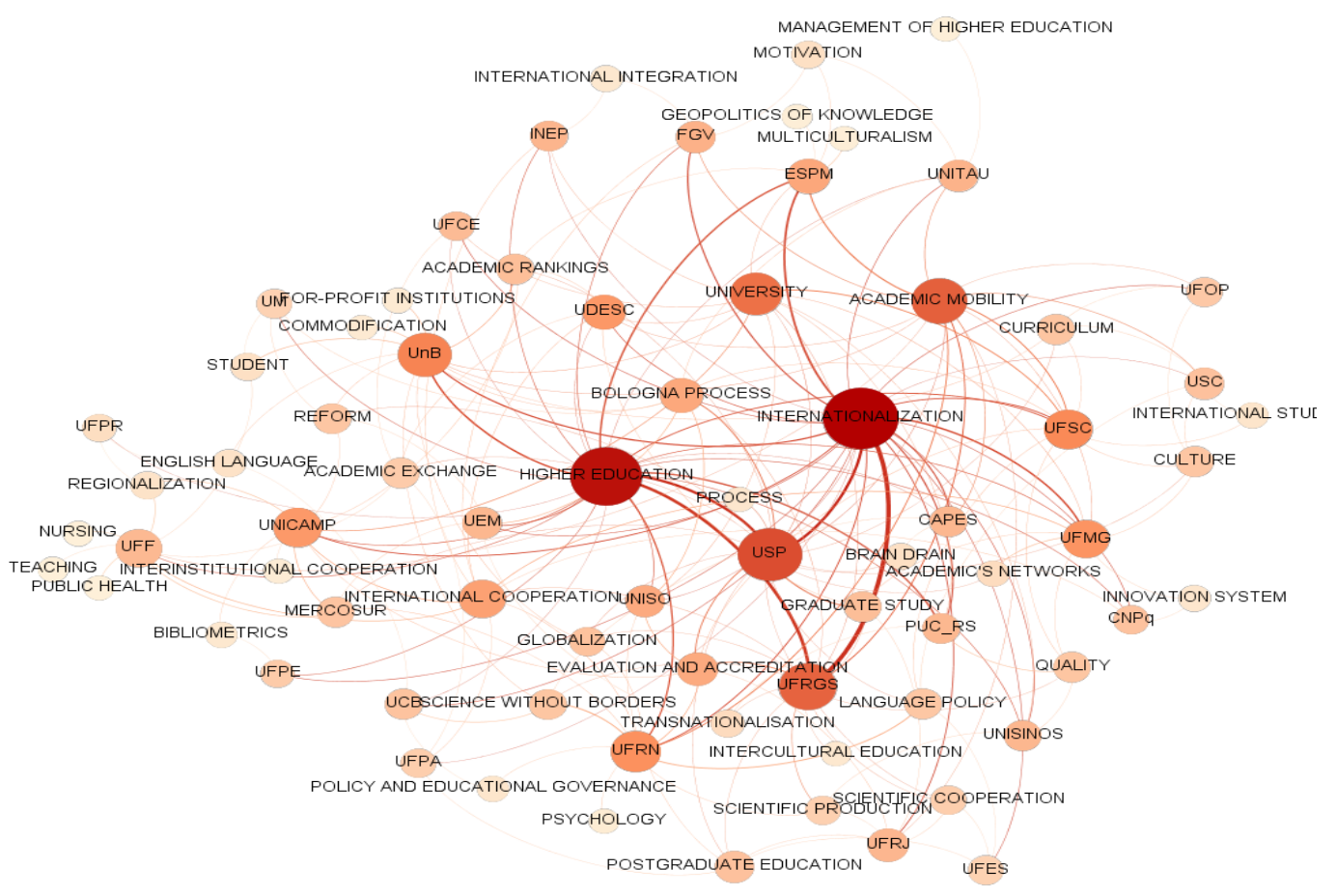

Fonte: Elaborado pelos autores (2018).

\section{Conclusões}

Neste estudo, levando em consideração a abordagem metodológica da análise de domínio, considerou-se o domínio científico Internacionalização da Educação Superior no Brasil como as imbricações intelectuais e sociais dos autores, instituições, periódicos e grupos de pesquisa materializadas no corpus de trabalhos produzidos por autores brasileiros sobre a temática. A configuração do domínio construído e interpretado pelos autores deste artigo é específica das fontes selecionadas e dos tipos de documentos incluídos no estudo, assim como das métricas de redes e visualizações elegidas. A subjetividade presente neste tipo de análise se contornou parcialmente com o contraste de resultados advindos do referencial teórico 
e de outros estudos que abordaram vertentes da produção científica brasileira na temática.

Os resultados aqui apresentados sugerem que, embora ainda relativamente pequena, existe uma comunidade de pesquisadores no Brasil organizando-se em torno do domínio Internacionalização da Educação Superior, formalizada inclusive em grupos de pesquisa certificados pelo CNPq. Contudo, a produção do conhecimento ainda parece fragmentada e desconexa, com pouca parceria internacional e disseminando-se em fontes quase exclusivamente nacionais.

A literatura existente sobre internacionalização da educação superior permite perceber as complexidades crescentes associadas a esse processo, atravessado pelos fenômenos de globalização e mercantilização da educação. Essas complexidades têm reflexões também nas contribuições brasileiras sobre o tema que atendem diferentes eixos, com abordagens e perspectivas variadas, incluindo visões que focam nas vantagens e possibilidades do processo para o posicionamento geopolítico do país, a qualidade da educação ou a integração latino-americana, enquanto outras alertam sobre os riscos de uma submissão aos regímenes hegemónicos impostos pelos países centrais e à logica mercantil.

O estudo visa continuar com a indagação dos referentes intelectuais das pesquisas brasileiras na temática para melhor aprofundamento na delimitação e caracterização do domínio.

\section{Financiamento}

O presente trabalho foi realizado com apoio da Coordenação de Aperfeiçoamento de Pessoal de Nível Superior (CAPES) - código de financiamento 001 e do Conselho Nacional de Desenvolvimento Científico e Tecnológico (CNPq) - Bolsa de Produtividade.

\section{Referências}

ABBA, Maria Julieta; CORSETTI, Berenice. Contribuições para uma internacionalização da educação superior desde e para América Latina. A experiência da UNILA e da ELAM. Educação por escrito; v. 7, n. 2, p. 181-200, 2016.

ALBRECHTSEN, Hanne. This is not Domain Analysis. Knowledge Organization. v. 42 , n. 8 , p. $557-661,2015$ 
ALTBACH Philip G.; KNIGHT, Jane. The internationalization of higher education: Motivations and realities. Journal of Studies in International Education, v. 11, n. 3-4, p. 290-305, 2007.

BRASIL. Ministério da Educação. MEC afirma que o Ciência sem Fronteiras terá 5 mil bolsistas na pós-graduação. 2017. Disponível em:

http://portal.mec.gov.br/ultimas-noticias/212-educacao-superior-1690610854/46981mec-afirma-que-o-ciencia-sem-fronteiras-tera-5-mil-bolsistas-na-pos-graduacao. Acesso em: 15 set. 2018.

CAPES - COORDENAÇÃO DE APERFEIÇOAMENTO DE PESSOAL DE NÍVEL SUPERIOR. Capes e CNPq apresentam avaliação preliminar do Ciência sem Fronteiras. 2015. Disponível em: http://capes.gov.br/sala-de-imprensa/noticias/7583capes-e-cnpq-apresentam-avaliacao-preliminar-do-ciencia-sem-fronteiras. Acesso em: 15 set. 2018

CARVALHO, Cristina Helena Almeida de. A mercantilização da educação superior brasileira e as estratégias de mercado das instituições Lucrativas. Revista Brasileira de Educação, v. 18, n. 54, p. 761-776, 2013.

DAL-SOTO, Fábio; ALVES, Juliano Nunes; SOUZA, Yeda Swirski de. A produção científica sobre internacionalização da educação superior na Web of Science:

características gerais e metodológicas. Educ. rev., Belo Horizonte, v. 32, n. 4, p. 229249, 2016. http://dx.doi.org/10.1590/0102-4698153246

DIDOU-AUPETIT, Sylvie. Introducción. In: DIDOU-AUPETIT, Sylvie; ESCOBAR, Vielka (Coord.). Internacionalización de la educación superior y las ciencias en América Latina: un estado del arte. Caracas: IESALC-UNESCO, 2014.

FREEMAN, Linton Clarke. The development of social network analysis: A study in the sociology of science. Vancouver: $\Sigma$ P Empirical Press, 2004.

HERMO, Javier; PITTELLI, Cecilia. Globalización e Internacionalización de la Educación Superior. Apuntes para el Estudio de la Situación en Argentina y el Mercosur, Revista Española de Educación Comparada, n. 14, p. 243-268, 2008.

HJØRLAND, Birger. Domain analysis in information science: eleven approachestraditional as well as innovative. Journal of Documentation, v. 58, n. 4, p. 422-462, 2002 .

HJØRLAND, Birger. Domain analysis. Encyclopedia of Knowledge Organization. 2017. Disponível em: http://www.isko.org/cyclo/domain_analysis\#ref. Acesso em: 27 ago. 2018.

HJØRLAND, Birger; ALBRECHTSEN, Hanne. Toward a new horizon in Information Science: Domain-Analysis. Journal of the American Society for Information Science. v. 6, n. 6, p. 400-425, 1995. 
KEHM, Barbara; TEICHLER, Ulrich. Research on Internationalisation in Higher Education. Journal of Studies in International Education, v. 11, n. 3-4, p. 260-273, 2007.

KNIGHT, Jane. Internationalization Remodeled: Definitions, Rationales, and Approaches. Journal for Studies in International Education, v. 8, n. 1, p. 5-31, 2004.

KNIGHT, Jane. The changing landscape of higher education internationalisation - for better or worse? Perspectives: Policy and Practice in Higher Education, v.17, n. 3, p. 84-90, 2013.

MARTINS, José Ricardo. UNILA: uma Universidade Federal Brasileira para América Latina. Ponto-e-vírgula, n. 7, p. 224-243, 2010.

MENENGHEL, Stela; AMARAL, Joana. Universidades internacionais na contracorrente. As propostas da UNILA e da UNILAB. Universidades, n. 67, p. 2540, 2016.

MONCADA CERÓN, Jesús Salvador. Hacia una internacionalización solidaria de la educación superior. Theoria, v. 20, n. 1, p. 21-32, 2011.

MONZÓN, Marcelo A. Internacionalización de la Educación Superior. Análisis y Acción: Apuntes para el desarrollo de un modelo Conceptual. In: TANGELSON, G. (Comp.). Desde el sur: miradas sobre la internacionalización. 1. ed. Remedios de Escalada: Ediciones de la UNLa- Universidad Nacional de Lanús, 2014.

MOROSINI, Marília Costa; NASCIMENTO, Lorena Machado do. Internacionalização da educação superior no Brasil: a produção recente em teses e dissertações. Educ. rev., v. 33, e15507, 2017. http://dx.doi.org/10.1590/01024698155071

OLIVEIRA, Ely Francina Tannuri de; GRÁCIO, Maria Cláudia Cabrini. Studies of author cocitation analysis: a bibliometric approach for domain analysis. IRIS, v.2, n.1, p. 12-23, 2013.

SAMPAIO, Helena; SAES, Paula. Internationalization of Higher Education: a balance of the literature in Brazil. In: DIDOU-AUPETIT, S; ESCOBAR, V. (Coord.). Internacionalización de la educación superior y las ciencias en América Latina: un estado del arte. Caracas: IESALC-UNESCO, 2014.

SÁNCHEZ-TARRAGÓ, Nancy; BUFREM, Leilah Santiago: SANTOS, Raimundo Nonato Macedo dos. La Ciencia de la Información y la Internacionalización de la Educación Superior. Informação \& Sociedade: estudos, v.26, p.73-89, 2016.

SÁNCHEZ-TARRAGÓ, Nancy; BUFREM, Leilah Santiago: SANTOS, Raimundo Nonato Macedo dos. La producción científica latinoamericana desde una mirada poscolonial. Tendências da Pesquisa Brasileira em Ciência da Informação, v. 8, p. 182-202, 2015. 
SÁNCHEZ-TARRAGÓ, Nancy; SANTOS, Raimundo Nonato Macedo; BUFREM, Leilah Santiago. Discusión sobre Políticas de Internacionalización en la Educación Superior: análisis de citas. Encontros Bibli: revista eletrônica de biblioteconomia e ciência da informação, v. 20, n. 44, p. 105-126, set./dez. 2015. http://dx.doi.org/10.5007/1518-2924.2015v20n44p105

SÁNCHEZ-TARRAGÓ, Nancy; SANTOS, Raimundo Nonato Macedo; BUFREM, Leilah Santiago. Internacionalización de la educación superior: una mirada a sus simientes intelectuales. In: ENCONTRO NACIONAL DE PESQUISA EM CIÊNCIA DA INFORMAÇÃO: ALÉM DAS NUVENS, EXPANDINDO AS FRONTEIRAS DA CIÊNCIA DA INFORMAÇÃO, 15., 2014, Belo Horizonte, MG. Anais... Belo Horizonte: UFMG, 2014. p. 30983118. Disponível em: http://enancib2014.eci. ufmg.br/documentos/anais/anais-gt7. Acesso em: 17 set. 2018.

SÁNCHEZ-TARRAGÓ, Nancy; SANTOS, Raimundo Nonato Macedo dos; BUFREM, Leilah Santiago. Internacionalização da educação superior no Brasil: mapeando um domínio. In: ENCONTRO BRASILEIRO DE BIBLIOMETRIA E CIENTOMETRIA, 6., 2018, Rio de Janeiro. Anais... Rio de Janeiro: UFRJ, 2018. Disponível em: https://ebbc.inf.br/ebbc6/docs/6EBBC2018v2018_07_27.pdf. Acesso em: 03 dez. 2018.

SHAPERE, Dudley. Scientific theories and their domains. In: SUPPE, F. (Ed). The structure of scientific theories. 2. ed. Urbana: University of Illinois Press, 1977.

SMIRAGLIA, Richard P. Domain analysis for knowledge organization: Tools for Ontology Extraction. Waltham, MA: Chandos Publishing, 2015.

STEIN, Sharon. Internationalization for an Uncertain Future: Tensions, Paradoxes, and Possibilities. The Review of Higher Education, v. 41, n. 10, p. 3-32, 2017.

VARGAS-QUESADA, Benjamin; MOYA-ANEGÓN, Félix. Visualizing the Structure of Science. Berlin: Springer-Verlag, 2007.

\title{
Visualizing and analyzing the domain of Internationalization of Higher Education in Brazil
}

\begin{abstract}
It characterizes and maps the networks of Brazilian researchers and their interrelationships based on their scientific production in articles and their participation in formalized research groups, in the domain of Internationalization of Higher Education. It presents a theoretical framework on the internationalization of higher education and the methodological approach of domain analysis. It uses domain analysis, combining bibliometric techniques, social network analysis and content analysis of textual corpus, consisting of 146 articles from scientific journals and conference proceedings obtained from Scopus, Web of Science (core collection and SciELO Citation Index), SciELO and Redalyc databases. It uses metrics and network
\end{abstract}


visualizations with Gephi 9.0.2 software. It verifies the existence of an incipient community of Brazilian researchers, already formalized in certified research groups, and organizing around the Internationalization of Higher Education domain. Their scientific production, though with little international partnership and predominantly disseminated in national sources, discusses relevant issues, reflecting that main concerns are related to geopolitics of knowledge, commodification of education and internationalization strategies.

Keywords: Internationalization of higher education. Domain analysis. Social network analysis. Maps of science. Brazil

Recebido: $24 / 09 / 2018$

Aceito: 03/12/2018 